\title{
Techno-Social Policy of Free Open Source Software in Turkey - A Case Study on Pardus
}

\author{
Hüseyin Tolu* \\ Computer and Instructional Technologies Teaching, Education Department, Recep Tayyip Erdogan University, \\ Çayeli, Rize, Turkey.
}

*Corresponding author. Tel.: +0090-545-4337106; email: huseyinalitolu@gmail.com Manuscript submitted October 25, 2015; accepted December 30, 2015.

doi: 10.17706/jsw.11.3.287-311

\begin{abstract}
Free Open Source Software (FOSS) is critical in any contemporary society, particularly if its digital existence is to be extensively crucial; therefore, it is essential to inquiry whether or not there is a credible and reliable FOSS-related Techno-Social Policy, in a particular context, as in Turkey. The study focuses on Pardus which is a FOSS-based Linux Operating System (OS), particularly arguing how Pardus has not achieved its initial or interim objectives clearly stated in 2004 and 2011; to become Pardus Fraud-Debian of becoming Turkey's present day accepted FOSS solution. To do so, the source for the study is collated from formal reports and internet data; and analyzed through application of process tracing approach to gain enhanced understanding. The study argues the causes relating to failure of the Pardus project and how this failure should be comprehended to conclude how Pardus was deliberately used as leverage to obtain better ongoing deals from Giants (e.g. Microsoft). This study shall then predict the outcome of the state-dependent FOSS project and inform the future FOSS project strategy and deployment. Consequently, the inquiry to whether or not there is a precise techno-social policy of FOSS is the subject of this paper.
\end{abstract}

Key words: Techno-social policy, free open source software, pardus, linux, Microsoft corporation.

\section{Introduction}

The principle of Free Open Source Software Movements is that if everyone has Linux, I will prefer to have Windows! Or more precisely, I will initiate 'Another' with Mine (or sincerely Our) Own Creativity!

Software scholars have already approved that software is the 'layer that permeates all areas of contemporary society' in which software study is a 'new movement and field of academic inquiry' [1]. In this sense, software is debatably either seeming as a rare knowledge (confidential software) or an ordinary resource (social networking applications). In some cases, it is acknowledged as both (quantum computing development)! Our contemporary society is formed by and dependent on digital world, in which we are all both suppliers and clienteles; in that sense, software is 'the life's blood of modern world' and 'the speed of life' [2]. Scholars also underline that we are essentially active in software societies irrespective of any particular software choice, and typically without taking into consideration to its own rational and logical consistency. For instance, the process of software development is an 'art' [3] and an impure 'living organism' that has techno-social pressures to our lives [4]. It is also independently technological; it has its 
own reasonableness and correctness in keeping with its own social transformation [5]. Nevertheless, within this complexity, what is clear is that software is classified into two broad families; Free Open Source Software (FOSS) and Proprietary Close Source Software (PCSS).

Currently attempting to evaluate the strengths and weaknesses of FOSS and PCSS, to any theoretical and technological depth, is challenging within the constraints of the imperfect market, and also mostly argumentative due to its malleable contemporaneousness. Nevertheless, the latest reports argue that FOSS is a real alternative of PCSS in terms of the global political-economic perspective [6], [7]. Fundamentally, "open cultures become the necessary condition for the system as a whole, for the design of open progressive technological improvements and their political, epistemic and ontological foundations." [8] So, FOSS is critical in any contemporary society, particularly if its digital existence is to be extensively crucial; therefore, it is further critical to study whether or not there is a credible and reliable FOSS-related Techno-Social Policy, in a particular context, as in Turkey. So, this study focuses on Pardus which is a FOSS-based Linux Operating System (OS), particularly arguing how Pardus has not achieved its initial or interim objectives clearly stated in 2004 and 2011; to become Pardus Fraud-Debian of becoming Turkey's present day accepted FOSS solution.

To evaluate Linux OS project experience in Turkey, it is essential to argue how and why Pardus was deployed and have become something else (Pardus Fraud-Debian), as a case study to perceive a new digital era from a national perspective. The source for the study is collated from formal reports (mainly government and parliamentary written questions) and the internet data (forums, blogs etc.) and analyzed through application of process tracing (PT) approach to gain enhanced understanding. This study initially presents PT approach, and then provides the story of Linux OS in Turkey. This study further argues the causes relating to failure of the Pardus-Linux project and how this failure should be comprehended to conclude how Pardus-Linux OSs was deliberately used as leverage to obtain better ongoing deals from Giants (e.g. Microsoft), in order to predict the outcome of the state-dependent FOSS project and inform the future FOSS project strategy and deployment. Consequently, the inquiry to whether or not there is a precise techno-social policy of FOSS is this paper subject.

\section{Process Tracing (PT) Approach}

"History matters not only because we can learn from the past, but also because the present and the future are connected to the past by the continuity of a society's institutions" [9]. History provides splendor information and links about social (currently techno-social) interactions; particularly post Internet, which keeps priceless recorded evidence. It may be impossible to clarify all, even in a specific subject; nevertheless, the internet (proof, data, etc.) may identify key concepts. For the methodology, this particular study used PT approach which comprises research where "the cause-effect link that connects independent variable and outcome is unwrapped and divided into smaller steps; then the investigator looks for observable evidence of each step" [10]. TP approach is actually for the purpose of uncovering "what stimuli the actors attend to; the decision process that makes use of these stimuli to arrive at decisions; the actual behavior that then occurs; the effect of various institutional arrangements on attention, processing, and behavior; and the effect of other variables of interest on attention, processing, and behavior" [11]. For PT, the author focused on interpreting (identifying and validating) the data, by taking a picture of a range of particular movements, to address and identify a series of interlinked phenomena, which cause and/or affect the outcome in this case-specific study.

Many PT scholars (like historical scholars) aimed to clarify a particular historical outcome, within a single-outcome study, on the basis of sufficient and complete evidences, through eclectic theorization; as is the aim in this study. The focus of PT is dissecting causation between detected variables. Predicating causal 
effects and causal mechanism on identifying causal inferences is the centre of PT. Causal effects is that a change in one aspect influences another change in the second aspect. It noticeably validates that changes are due to a particular cause. It is thereby critical to understand the continuous process. Nevertheless, a variable has no one particular causal effect on a causal inferences unless there is an essential causal mechanism, and there is no meaning to identify any unit as a causal mechanism if there is no one particular causal effect. So, causal inferences are the conclusion of the reasoning that something is, or is probable to be, the reason of something else because in PT "neither theories nor cases are sacrosanct. Cases are always too complicated to vindicate a single theory, so scholars who work in this tradition are likely to draw on a mélange of theoretical traditions in hopes of gaining greater purchase on the cases they care about. At the same time, a compelling interpretation of a particular case is only interesting if it points to ways of understanding other cases as well [12]."

\section{Linux OSs in Turkey}

The Linux community started to organize itself in Turkey in the early 1990s, in the list of (linux@bilkent.edu.tr). Significantly, in 1995 the first coordinated gathering of minds met at 'the Internet in Turkey Conference'. By 2000, the 'Turkey Linux User Group' established 'Turkish Linux User Association' (LKD), which defined itself as "a non-governmental organization in Turkey, created by people who believe in free software and aims at acting together by sharing knowledge and experience" (lkd.org.tr/en). LKD embraces GNU/Linux philosophy and also supports all other FOSS licenses and projects. LKD conducted the first 'Linux and Free Software Festivity I' at the University of Ankara. This is now an annual event throughout Academic institutions in Turkey (ozguryazilimgunleri.org.tr).

As a result of LKD, further volunteers started to seek how to develop Linux distro which might answer the requirements of Turkey. A group of students at ITU and Yeditepe Universities first started to develop Linux distro, named Turkuaz-Linux in 1997-1999. The aim was to get Turkish localized an OS and software'. Turkuaz-Linux was based on RedHat. 495 software packages were localized, and distributed with personal computers (openhub.net/p/turkuaz). The all aims were not achieved, but led to new projects, e.g. Gelecek Linux was developed based on RedHat by Gelecek Cooperation as commercial Linux distro. Turuva Linux is another Linux distro introduced since April 2004. Although, there have been many FOSS projects from Turkey (more FOSS projects, linux.org.tr/-yerel-ozgur-yazilimlar), the most comprehensive FOSS project is the Pardus project, introduced by the Scientific and Technological Research Council of Turkey (TUBITAK) since 2003. Pardus project history is so problematic to analyze due to complexity of understanding FOSS movements and philosophies, community relationships and conflicts, interventions from TUBITAK and Governments, etc. Therefore, many FOSS supporters publicly state that Pardus made us salivate, but not eat! In this sense, it is essential to critique all opinions in the public domain.

\section{A Misdirected Journey}

In December 2002, Görkem Çetin and Ali Işıngör published a satirical article in the M5 Magazine, entitled 'Does Your Army Still Use Your Mothers OS?' [13] Subsequently, in March 2003 the Prime Ministry appointed TUBITAK to complete feasibility studies for developing 'national' OS. In September 2003, TUBITAK announced UluDağ Project (called National Distribution Project) whose aim was to scope the feasibility of developing a national OS rather than actually developing it. Within six short months, the project team has widened the scope of the project to develop Linux-based OS. After technical investigation, the project team released 'Project Master Agreement' in October 2004, and revised the terms of the UluDağ Project as the Pardus project (scientific name is Anatolian leopard). The dominant media declaration was declared by the Prime Minister, Recep Tayyip Erdogan and subsequent Ministries since 2004 as 'Turkey is 
going to use its own OS'.

The Ministry of Development stated that in 2003-2009, 3.5 million TL and in 2009-2011, 14 million 310 thousand TL was given to the Pardus project; and importantly claimed that only the Ministry of Defense has had savings of $\$ 2$ Million through the use of Pardus [14]. There are also other various public and private institutions that have since used Pardus (see the list of public and private institutions used Pardus, from pardus.org.tr), particularly the Ministry of Justice, Energy Market Regulatory Authority, Radio and Television Supreme Council Corporation and the Ministry of Environment and Urban Planning, etc. When Pardus had its sixth birthday in 2010, Pardus was ranked the fifth best Linux distro in three categories by Readers' Choice Awards 2010 in the Linux Journal, which is the most prestigious publication across the world [15].

In 2004, four developers only started to localize Linux-kernel. By 2009, seventeen employed developers and more than 200 active developers contributed to the Pardus development process, where $59 \%$ of its content was voluntary developed [16]. Pardus 2011 supports eleven languages, and meets nearly all the needs of regular internet and computer end-users. Pardus was localized from Linux kernel and Linux features in accordance with Turkish culture and society until 2008, after than the Pardus community not only contribute towards global FOSS projects but also develop their own projects, e.g. COMAR, KAPTAN, etc.

During the process of restructuring TUBITAK and Turkish National Academic Network and Information Centre (UEKAE) since June 2011, many developers in the Pardus project began to resign because they could not agree on strategy and/or the development process and pace was overwhelming. Only a small percentage of resignation reasons were disclosed due to the restriction of nondisclosure agreements enforced as an employee or contractor of TUBITAK. Although most left voluntarily, some were 'asked to leave'. It was commonly known that morale and motivations of the team declined and the development progress of Pardus was severely hampered. Post December 2012, in the Pardus team, there were less than five remaining developers. Meanwhile, TUBITAK continually declared that TUBITAK had no intention of withdrawing from the Pardus project; nevertheless a reduction of 31 developers in six months in the Pardus team would have indicated a problem. In early February 2012, with a drastically reduced team, the Pardus team declared no ongoing support for their 2011 version. That means that TUBITAK abandoned Pardus 2011 without releasing a new version and this action would indicate that the Pardus project had already been cancelled in February 2012.

The Pardus project has attracted much criticism from all stakeholders (i.e. users, developers, communities, academicians, bureaucrats, Ministries, etc)). Therefore, in advance of 'Pardus Tomorrow Workshop' held by TUBITAK, relevant parties were invited to underline their own criticisms of the Pardus project and to give recommendations for redefinition of the project strategy. In March 2012, in response, 'Pardus Critics Report from Users and Developers' was released [17]. Arguments were also introduced within the forum title of 'Youth Developers are Uncomfortable'. The 'Pardus Tomorrow Workshop' was held on 23-24 March 2012, promoting the slogan of 'Pardus is not dead, and will be living greater'. At the workshop, criticisms were analyzed quantitatively as follows [18]. As many are a regular Pardus user and reader, we are already aware that the majority of criticism is from the Pardus developers and active FOSS communities. The author generally agrees with much of the criticisms that was presented but disagree on the priority/order of importance. Where the author opinion has different from the source, the author has attempted to expand the argument below.

\section{Abounded Pardus}

\subsection{Project Management Failure (129 Votes)}


The history of the Pardus project is clarified by Tekman, who was the manager of the Pardus project, in his articles: 'Not So Fast ...'; 'Pardus Unfavorable History'; 'Pasha Gas Finished...!'; 'Did Pardus Throw up the Sponge', etc., on his blog [19]. These are significantly detailed articles; therefore the author has prioritized the salient points he raises. According to Tekman, the Pardus project has 'failed' because of critical decisions taken in the second project quarter (2007-2010, migration studies). Tekman does not blame the first quarter decision to pursue PISI development structure (the package manager system); though many believe differently, as further argued. The Pardus project is "a business, not a science project", therefore Tekman attempted to integrate the Pardus project with hardware and software manufacturers, and training and consulting firms, to create business platform. Tekman believed that 'someone has to gain profits to make Pardus alive' (commercial purpose investment). He also wrote an article called 'Six Success Factors for National Open Source Projects', subtitled into Finance, Team, Product, Community User and Policy, and further presented a SWOT analysis for the Pardus project in December 2008. His arguments endeavored to redefine the Pardus project and associated forums as working towards a profitable business solution or, as a minimum, attempted to redefine the project as business oriented. Tekman also perceived other Linux distros as an enemy, or at least as a competitor, particularly the Ubuntu project. Nevertheless, Tekman's only correct insight was when he stated that TUBITAK was the first obstacle for the Pardus project, and provided limited support, as argued further.

In response to Tekman's views there has been much criticism. Tekman created personal conflict through his dogmatic unwillingness to negotiate and consider feedback; his understanding of the project terms of reference and his decision-making style and rationale made him unpopular. Furthermore, rumors about the project inferred corruption. Tekman does not accept these criticisms; calling his colleagues liars and opportunists. For instance, he stated that some developers left because 'all these years, we have developed, people used, a little, others develop and we eat' [20]. His quote supports a widely reported issue with his project leadership skills. The following criticisms also show clear project management failure.

\subsection{No Contributions from Outside (118 Votes)}

Pardus has been developed by mainly volunteers in Turkey, and TUBITAK contracted workers, resulting in project management failure and decision to develop PISI; this was a barrier to international volunteers. As a nature of Linux, projects must be international otherwise it is nearly impossible to follow technological changes, even if the project team has over hundred developers, e.g. It is difficult to categorically state how many developers Ubuntu used, but it is commonly known that the Ubuntu team generally consisted over 20 contracted developers, over hundred active voluntaries and thousands of passive developers. So the Pardus project could not be an international project.

\subsection{Lack of Specific Policy (109 Votes)}

In the project, GNU/Linux philosophy could not be interiorized. Initially, the principal agreement of the Pardus project was defined in October 2004 [21] and redefined in June 2011 [22].

The project visions were, 2004: Pardus is a GNU/Linux distro which is developed by TUBITAK, targeting the needs of computer users with basic desktop computer literacy; through using superior features of present Linux distributions: concepts, architectures and codes; and making Pardus an evaluated autonomous system, framework and tools to ensure ease of installation, configuration and use. 2011: Pardus is aimed to develop a competitive and innovative Linux distro through using free software approaches and methods for institutional users; and provide products and solutions of distros needed in institutional market by a direct (Pardus team) or free software ecosystem.

The project assumptions are as, 2004: (1) the project is a Free Software Project licensed under the GPL; 
(2) the project is carried out as open to the public in accordance with free software philosophy and so help of voluntary contributions are used; (3) the project can transfer architectures and components of other Linux distributions, and directly use open source projects (distribution independent); and (4) the project directly uses outcomes and products of localization studies for free software (translation to Turkish). (2011): (1) the project is carried out as open to the public in accordance with Free Software Philosophy; (2) the project products are freely distributed under the GNU/GPL license; (3) the studies and developed products in the scope of contracted projects by TUBITAK may create an exception of the above substances; and (4) Pardus project will primarily target the Turkish market.

There are also missions, limitations, sources, constraints, risks and working conditions in the principal agreements. Nevertheless, it is evident that the Pardus project was started under GNU-Linux project (2004) and has become a GNU-Business friendly project (2011), which is totally contradictory to FOSS philosophies. Importantly, for any projects which are undertaken by TUBITAK and contracted developers, where some part may become proprietor software, the concept of licenses is classified.

Importantly, the Pardus project was developed in contrary to FOSS movements. The above two principal agreements, which were declared by TUBITAK, but not unanimously accepted by FOSS communities in Turkey and subsequent decisions taken by the Pardus team, were also not aligned with FOSS philosophies. For instance, in 2010, the Pardus team made the decision to use JIRA close software in the project (many critiques of JIRA and Pardus are shown in Google searches). The decision to use JIRA closed software was so controversial in FOSS communities, particularly by LKD, since 2007, because there were arguably acceptable FOSS alternatives. The majority of voluntary developers withdrew support for the Pardus project and some Pardus team developers resigned after this decision. Briefly, the Pardus team used JIRA because, although closed software, its license allowed being part of Pardus, and other FOSS alternatives were not mature/developed enough. On evaluation, either TUBITAK or the Pardus team decided to use the available closed option of JIRA, instead of developing another FOSS application or improving its' alternatives. TUBITAK or the Pardus team justified their decision to use JIRA's closed software by claiming that there are other FOSS projects; such as Apache using PCSS products as well. This did not address the ethics of blatantly ignoring GNU-philosophy and their own objectives. Internally, management within the Pardus team was criticized voluntary developers for not developing an alternative of JIRA [23]. Voluntary developers could not develop an alternative, due to their lack of liability provided by the Pardus team. The full time workers, who had financial support, could not accept liability to develop an alternative of JIRA. Much internal cross group criticism was recorded. LKD ironically described the Pardus project as Free Software with Pragmatic decisions, where there was no autonomy within a civil service cultured team. The author has summarized the various complainant themes, rather than quoting verbatim excerpts, as censorship and strong language make this impossible.

Additionally, there was no study related to Pardus Project Policy in Public Institutions (see Evaluation Report V, the chapter the Use of Open Source Software in Public Institutions, March 2010 by State Planning Organization [24] and the 25th Meeting of the High Council of Science and Technology Report, January 2013 [25]), e.g. there were many comprehensive FOSS projects completed by the Pardus team, in which Pardus team took responsibilities of all these projects, despite TUBITAK always emphasizing they were FOSS ecosystem projects. In this sense how many projects could the Pardus team take to support projects with a small team? So the Pardus project was also developed in contrary to FOSS ecosystem.

\subsection{Being Incapable of Getting Support from Universities (103 Votes)}

Although there have been many conferences about FOSS and the Pardus project at various universities up to now (ozguryazilimgunleri.org), the project has been supported by few universities mainly due to lack 
of networking capability in academia, e.g., Dr. Yücel at Computer Engineering Department at the COMU University founded a voluntary team in February 2010 to complete 64 Bit Pardus Project, to port Pardus Institution-2 version to 64 Bit system architecture. Following success, Dr. Yücel founded another team in October 2010 to complete Multi-Desktop Setup Project (ÇoMak) to make Pardus technologies independent from KDE desktop platform. In 2011, through an agreement with University of Bahçeşehir, Pardus usability tests were completed, aimed to prepare a more usable and consistent interface guide. The Pardus team was willing to collaborate with the KDE usability team. Previously, the Pardus team had a similar agreement in principle with Yildiz Technical University, but it had not been possible to deploy due to a number of bureaucratic obstacles. The agreement with Yildiz Technical University was released in (lists.pardus.org.tr/-gelistirici/2010-July.txt) which was previously the Pardus team conversation forum; however there is conflicting information from özgürlükiçin.com with e-journal July 2009 by TUBITAK. This suggests discord between the Pardus team and TUBITAK. These limited examples of academic collaboration are far fewer than would be expected on a national project of this size.

It is commonly known that Microsoft has provided donations, particularly free products and services for universities. Although universities in Turkey have not been considered as donor candidates for software for some time, since 2012 the Microsoft has been directly investigating all universities with its lawyers, to force them to pay all licensed fees. This is evidently one of Microsoft marketing strategies. The outcome was that Microsoft was very pleased with culture of universities in Turkey, as all students, in all specialists, have studied Microsoft platforms and products and graduated Microsoft skills and knowledge. Consequently, the majorities wish to extend their license privileges into their professional careers but inertia restricts many from looking for alternatives. Barriers to exit and entry restrict end-users' ability to switch suppliers/solutions that still meet their needs, particularly non-ICT experts. In this sense, universities are crucial influencers. Microsoft is obviously aware of this power, and sponsor academic institutions to provide free charged software and even open Microsoft centers at universities. However, since 2012 Microsoft has changed its strategy. Dr. Yücel called it as the War between Microsoft and Universities. In universities, Microsoft considers all lease payments for each OS to be insufficient recompense; therefore Microsoft has begun working through the court to increase the gain. Ali Aydin, the lawyer acting on behalf Microsoft, has sent a cover letter, requesting an inventory of OSs at all universities. The letter requires a response within 14 days and ends with 'Warning' and 'Notice'. Microsoft's lawyer, an expert and a judge all undertook an adhoc audit visit to a university in Turkey, they were in court. The expert report was not determined; nevertheless, it was widely spoken that the process would be introduced for adhoc visits to other universities [26]. However, nothing happens until now in Turkey that indicates how Microsoft's strategy worked out for Microsoft benefit.

Legally, Competition Law may choose to restrict the Microsoft from offering Government institutions (including universities) different solutions at different prices or offering universities free services. The outcome of Competition Law decisions need to be answered but not within the scope of this research. It was actually the case that Microsoft is testing the power of negotiating with the Governments regarding the Fatih project (the biggest and current techno-educational project in Turkey), to both influence the Government choice of Android technology and to influence (make dependent) a new generation of stakeholder [27].

Returning to the subject of the Pardus project collaboration; it is understandable that universities have not provided any support for the Pardus project because their academics generally possess only Microsoft platform knowledge and skills, committees of universities might simply perceive that universities must train personnel for public and private sectors, so students must know Microsoft and PCSS products only. Funding research restricts pursuing objectives outside of these parameters. For career prospects, the ICT 
academics prefer to use and develop PCSS products for their commercial value and economical gain. The question should be why other universities, that have been supporting and developing FOSS projects for two decades, such as, Istanbul University, Inonu University, etc. do not support the Pardus project. Academics might reason that the purpose of the Pardus project does not fit with FOSS philosophies and movements, so they prefer other Linux distro.

\subsection{Unnecessarily More Dependent on TUBITAK (100 Votes)}

TUBITAK has never shared any power with knowledgeable FOSS communities in the decision-making process, as also argued further in the second section of the paper. Frequently, FOSS communities have been informed after decisions have been finalized, e.g. PISI, Pardus Fraud-Debian etc. In 2012, Former developer, Kandemir explained issues as, "TUBITAK was the reason that project not being successful as Ubuntu or Fedora, but also it was the reason that an open source project lived more than 5 years in Turkey" [28]. Is there any sense in TUBITAK overseeing the success of the Pardus project, when they are so reliant on its success within imperfect market competition and unsupported and fake state support? TUBITAK's relativity/dependency on the Pardus project is conducive to producing Open Source Software but not necessarily totally 'Free' software. FOSS developers write and share codes with others to improve it. Evidently the project has been perceived as a business not a science as Tekman stated. Although there are always license agreements, developers do not consider them as much as TUBITAK did. For instance, did LKD ask any permission to open Linux User Association from Linus Torvalds?

\subsection{Target Audience Selection (100 Votes)}

The target audience for the Pardus project was computer end-users with basic desktop computer literacy in 2004, but strangely the overall 2004 missions were to protect national independence, security and savings. In 2011 the target had become only institutional users. In any Linux project, targeting all end-users and all institutional end-users is, at this initial stage of development, too wide a scope to realistically meet the need of all end-users. The target suggests that that they were aiming Pardus to replace the need for Windows. This created unrealistic expectations within all Ministries when defining their future-proofed ICT strategy. Tekman also confessed that the Pardus project aspirations intentionally created vain hopes [29]. However, Linux is Linux and should not be understood as a clone of Windows. This is also a common misconception in FOSS community. Why are Adobe products not compatible with Linux? Why is Skype not working with Linux? Etc. Because they are PCSS products and FOSS movements have their own software or alternatives projects as diverse as these PCSS products. From the end-user perspective these can be an understandable desire, but shaping GNU-Linux project in this ways is inconsistent and unprofessional.

\subsection{Wrong Approach for Relations with Communities (100 Votes)}

TUBITAK sued one of the biggest FOSS communities in Turkey in order to assert their power as a leader within the FOSS community. The Pardus team was heavily criticized, both politically and professionally, for their very aggressive presence within the communities, as a result of both wanting to dominate and being perceived as specialist experts a structure-less community. Their resulting poor behavior may have been accepted as typical of the global FOSS community, but it was unacceptable conduct within the Turkish culture. The Pardus team (including voluntary developers) did not correctly coordinate and manage their public profile with skilled and unskilled external communities and nor did they publish their own 'Open Respect Declaration' as other Linux movements (see openrespect.org). This was perceived as project mismanagement, lack of leadership within the project and intimidation and elimination of voluntary contribution within Turkey. 


\subsection{No Providing Training Programs (93 Votes)}

In the Pardus project, Tekman defined Pardus ecosystem in 2009 through Pardus Migration Partners, Software and Solution Partners, Hardware Partners and Education Centers. Regarding of educational projects, Tekman stated that all Pardus training would target professionals, and were designed for the purpose of career development. The training program courses were specifically designed to the specific job role within ICT market. Post training, supervised certification exams would be held by TUBITAK. Tekman stated that current (2009) TUBITAK certifications were: Pardus Support Staff, Pardus Support Specialist, Pardus Users' Trainer, Pardus System Managers, Pardus System Specialist and Pardus Developers' Trainer. It was also claimed that TUBITAK would develop Pardus Driving Curricula like European Computer Driving License with Public Education General Directorate in the Ministry of National Education (MoNE). The training would be completed through Pardus Education Centers [30]. To date, (2015), these educational projects were planned by TUBITAK since 2008 but no professional training, as described above, has been implemented by TUBITAK by 2015. So, there is a lack of training programs (few) to pardus communities and so no contributions.

\subsection{Making Pardus with National Concerns (87)}

The Pardus project is always alleged as a National OS since 2005. The Pardus team have corrected this misconception, stating 'Pardus is not a National OS; actually it is a National Linux Distro'. Many people believe that calling Pardus OSs a 'NATIONAL' Linux Distro is misrepresentative; it has been developed by the Turkish but its former definition of being a Linux-based OS and free does not lend itself to being described as nationally owned, just a nationally distributed Linux Distro. Tekman, TUBITAK, Politicians, Ministries, bureaucrats, etc. kept referring to Pardus as National OSs. They promote Kemalism, Nationalism and Turkism instead of FOSS philosophies, e.g. primary public slogans were Turkish developers develop Turkish OS and they promote a Turkish desktop presence (i.e. Turkish flag, anthem, Atatürk, etc.) despite no Turkish desktop presence in the release. Many nationalistic stakeholders in Turkey believe it creates awareness and perhaps adoption of Pardus OSs through linking Turkish pride. Tekman stated in an interview that one percent of Pardus OSs has been developed by the Pardus team [31]. Nevertheless, one percent is an exaggeration. Despite this, he describes Pardus as a national product. It might also be arguable that Turkish translation has not been successfully translated in Pardus. If we compare LibreOffice translation, as a global FOSS project, the Interface content is $100 \%$ and help content is $99 \%$ Turkish language accuracy and 5.329 words need translation during February 2015 (see Turkish LibreOffice Translation from translations. documentfoundation.org/tr/). These figures change with period updates. Notably LibreOffice translation has been voluntarily completed by 'Translation Night Team' who is mainly organized by Zeki Bildirici, outside of the contracted Pardus team.

The national concerns and interests link in the Pardus project also resulted in unintentional consequences, e.g. there were live discussions about why Pardus, developed by public tax, does not support the Kurdish language, while Pardus 2011 has supported eleven alternative languages. Even a student in Turkey translated Ubuntu to Kurdish and publicly released codes and information. At the same time, within the Pardus community (ozgurlukicin.org) was controlled by TUBITAK (2007-2011). There was so much censorship of forums, particularly deleting commands, restricting users etc. that voluntary developers became despondent and disassociated with the project (many critiques of Kurdish language support and Pardus are shown in Google searches). Censorship continued until (ozgurlukicin.org) become independent from TUBITAK in June 2011. Notably some contracted developers in the Pardus team supported voluntary developers' contributions within the project, in order to support Pardus as many languages as possible. 


\subsection{State Has Not Supported to the Project (87 Votes)}

International Development Association states that "'If your attitude to IT is 'Who do I sue when things go wrong?' the document concludes, then perhaps OSS is not for you." [32] In 2005, MP, Muharrem Toprak in Turkey's Opposition Party stated that 'close source software is an analogue of using drugs without knowing their contents!' [33]. Since then opposition parties have submitted various parliamentary written questions on generic software (over three hundreds [34]) during three main periods: (a) pre \& post Bill Gates being invited to visit Turkey, and coinciding with the first Pardus OS issue in February 2005; (b) One year later, when the first stable Pardus OS institutional version was released in 2007; and (c) after the Fatih project was announced in 2011. In Turkey, the Justice and Development Party (AKP) has been the incumbent Government since 2002, so all these reports reflect AKP views regarding Linux OSs. Contrary to the common perception in Turkey, reports show that not all Ministries support FOSS and Linux OSs and some of them clearly have opposed FOSS and FOSS philosophies in terms of economic perspectives. There is no particular harmony across Ministries of Turkey regarding use of Linux, when considering a culmination of these reports; the Government has attempted implementation of pragmatic decision strategies through considering global political economy and technological changes regarding ICT, and so software. E.g. in 2008 the Ministry of Environment and Forestry stated that Linux software applications are still in the development process. Providing so much effort and then giving all these as a public good- GPL are still ongoing conflict' [35].

Within all parliamentary documents, MoNE clearly clarified the culture of ICT on behalf of all Ministries and for the Government (twice in 2005 and 2008) as that 'the fundamental principle of MoNE Ministry is to integrate hardware and software tools, which have proven their reliability in Turkey as well as world-wide, into education and training activities without dependency on a particular company's products and services. Providing these basic principles is for the prevention of monopolization in the private sector and contribution of competition in the environment. In line with these principles, in the Ministry, either in central organizations or in education and training institutions, the best and the most reliable products are taken from companies which have the most common service networks, with the cheapest prices by competing in a healthy environment through various private sector institutions and organizations in wide range of different products. In this sense, the Ministry reveals strong determination. While the ICT sector advances rapidly, its main goals are to provide ICT culture to students, whilst keeping open source software in balance as much as possible. While Microsoft products are being used in some units of Ministry, there are ongoing studies to contribute developing Linux OS for using open source software in some units of the Ministry. The main purpose of these indicated efforts is the acquisition of software culture for students and the Ministry workers with using various open source software developed by various platforms' [36].

It is clear that the MoNE sought the best and the most reliable products within the best price, whilst keeping open source software in the balance for creating ICT culture for students. However, FOSS is never perceived as a real alternative of PCSS; FOSS is just utilized to broker better deals. According to MP, Erdal Aksunger, the 'strange bureaucrat chain' is the first main obstacle in the Pardus development. In his speech in parliament in 2012, he stated that bureaucrats are stopping use of Pardus OSs in institutions because of their own unwillingness and anxieties. In public procurement authority, bureaucrats perceive PCSS as a commodity and FOSS as a service only [37]. In the parliamentary reports, the discourse of Ministries is a 'one-size-fits-all-software-system' as a procrustean bed. However, a one-size-fits-all-software-system cannot be applied to ICT, and is not the most effective solution in ICT. The differing requirements of a nation, current and future cannot conform to one-size-fits-all; ICT is naturally unstable and unmanageable; different software works better in different settings, and there are lock-in issues, etc. Notably FOSS is not a tailored one-size-fits-all system. The Prime Minister/State Planning Organization (SPO) in 2008 stated that 
'making regulation for the use of Linux OSs (particularly Pardus) as imperative in all public institutions and organizations is not considered in a short period because it is evaluated as nonenforceable' [38].

Most Ministries have started Microsoft platform dependent projects and never believed in the Pardus project, even TUBUTAK itself. In 2008, TUBITAK declared that Pardus OSs was used in all personal computers and laptops which were not in the TUBITAK-UEKAE Intranet system. For intranet systems, they had some software applications developed for various specific purposes. For this software, Pardus migration plans were prepared and conversion studies were continuing. After completing all of these studies, TUBITAK-UEKAE would use Pardus OSs in all hardware and recommend using Pardus into all TUBITAK institutions [39]. Strangely, developing Pardus OSs was started since 2003 and in 2008 TUBITAK was still professing an undefined and unclear position. According to Akgül, 'migration to FOSS is depending on being ready for change, and a social leader. In Turkey, I cannot state that Turkey has work of leaderships. TUBITAK which supports and funds Pardus does not use Pardus that much. For instance, in one period the license cost of office applications was very expensive and TUBITAK did not want to pay it, therefore they were migrating to StartOffice/OpenOffice. Then Microsoft let the software free of charge for TUBITAK. Immediately TUBITAK returned to Microsoft Office' [40].

One of the latest perspectives from TUBITAK regarding FOSS is also unexpected. In February 2013, TUBITAK have started '2024 Software Projects Competition for Undergraduates', to encourage and to provide opportunities for students who are willing to improve their knowledge and skill, as well as for the purpose of developing innovative and entrepreneurial culture at universities. However, the Competition Guide Report initially stated that products which are produced by Open Source Software (OSS) cannot participate in this contest. In any case of OSs detection, projects would be eliminated, regardless of project stage [41]. According to Dr. Yücel, he personally rang TUBITAK to ask the reason of unacceptable OSS exclusion. TUBITAK reasoned that 'how TUBITAK could be sure that codes are written by you when in OSS'? Their reasoning is illogical when considering accuracy of authorship is also applied for in PCSS. How can TUBITAK be sure that codes are not copied or altered from close software? [42]. After, Dr. Yücel's criticism, TUBITAK changed the imperatives as products which are produced by Open Source Software (OSS) cannot participate on this contest if there is no development/adaptation. Projects developing Open Source Software or developing Open Source Software products are not left out of the scope [43]. Evidently the individual developer relationship is the crucial concept for FOSS, but definitely not enough to be balanced between FOSS and PCSS. TUBITAK has little or no FOSS support, and TUBITAK has never used the 'Free' description (reflecting both free of cost; freedom to run, read and study software for any purposes as well as free speech; freedom to modify and share copies of software; both original and new version under the same license agreement), and restricts their definition to 'Open Source Software' only. To question the National ICT Policy, or specifically FOSS National Policy definition/scope should be another research question and beyond this study purpose.

Besides this contradictory and disingenuous support (for FOSS) from TUBITAK, Bureaucrats within Government organizations were also humiliating the Pardus team, in April 2012, Arslan who was a former Pardus developer, blogged that 'in the workshop, when I hear '501 Developer', I feel sorry. It is not a bad thing to be a '501 Developer'; however it saddened me to be accused by TUBITAK as working that way for years. Because, as everyone who took part in the project knows, the team worked hard regardless of nights, days and weekends. It was pleasure to work after hours, even if this was completed at home. Moreover, many of the team members were volunteers or volunteering extra hours. It was not nice to be accused of being a 9-5er and we needed enthusiastic people' [44]. Although the Pardus team was legally restricted (through non disclosure agreements) from sharing their project experience, there have been various blogs shared by the Pardus team which mirror Arslan's. Their comments have been widely discussed in FOSS 
communities. Sometimes developers were accused of being emotional and/or politically for or against the project. In March 2010, Gorsel, who was a former Pardus developer, published a quantitative report, titled 'When We are Developing', to respond to the ongoing and relentless 501 developer humiliation [45]. To demonstrate the disingenuity of state FOSS support, an important example is the discourse of Binali Yildirim who was the Minister of the Ministry Transport, Maritime Affairs and Communications in Open Academy Press Conference in January 2012. (Notably, the Minister was sitting in front of the platform which was promoting Microsoft and Open Academy posters). The Minister stated that 'Microsoft is the best known and the most common. In the scope of the Fatih project there is no obstacle for Microsoft Corporation. Two OSs are going to be in the system. A 'wanter' uses Microsoft; a 'wanter' uses Pardus which is such a thing developed by TUBITAK, Question; in other words, different OSs will be available in 14 million tablets (the Fatih project). Minister: will be; it should be. In my opinion, it is necessary. However, the MoNE is responsible for that; therefore we need to confirm it from them. I accept it as a warning. We will discuss this issue with colleagues' [46]. The power link is obvious. Nevertheless, require to elucidate that 'wanter', if specified Microsoft default, is not able to 'choose' Pardus.

\subsection{Marketing (76)}

There is no documented initiative by TUBITAK to enter into relations with ICT vendors; in order to persuade them to preinstall Pardus in their own products. It could have been accomplished but no comprehensive initiative has been launched. Indeed, the private sector in Turkey has attempted to accomplish this mission, but was not successful, e.g. there are nine direct applications to Turkish Competition Authority (see rekabet.gov.tr) against the Microsoft Corporation and the Microsoft Ireland Operations regarding abusing dominant position in ICT market. The first applied case was in 2002 and the last was 2012. The Competition Authority stated 'it is unanimously decided that there is no need to open an investigation'. For instance, the Gelecek Inc. challenged three cases and two court decisions against the Competition Authority, in regard to their above decisions about Microsoft's anti-competitive behavior, since 2005. The Gelecek Inc., claimed that (a) the Microsoft Corporation forced distribution channels (PC manufactures, large end-users stores etc.) to prevent the promotion and sale of Gelecek Inc. products; and (b) the Microsoft Corporation monopolized distribution channels (PC manufactures, large end-users stores etc.) to sell only Microsoft products by providing encouraging and rewarding mechanisms (reduction systems, refunds, etc.) again resulting in the prevention and sale of Gelecek Inc. products. Notably the Gelecek Inc. presented its products based on Linux. Consequently, one of the primary aims of the Pardus project, to preinstall Pardus on laptops/computers to end-users, could not be realized due to the Microsoft Corporation/the Competition Authority actions. Despite being a nationally recognized and supported project, this indicates a lack of will or power for the Turkey's Competition Authority to influence or control Microsoft's anti-competitive dealings.

Despite Microsoft's aggressive marketing, there have been some effective marketing campaigns completed by FOSS communities, e.g. 'Come, we will install Linux in your computer', 'Linux summer camps', 'Send Pardus CD project', etc. There have also been some small successes in terms of challenging Microsoft dominance. For example, two court cases challenging Microsoft products have resulted in returning the OSs products. The first court case in August 2008 was started by Attorney Karslı who is the president of Pardus User Associations (PKD) (see tr.pardus-wiki.org and Isletim_sistemi_iadesi). Both court cases were successfully completed by PDK as precedent test cases. Nevertheless, the process of bringing these cases to court is so resource draining that manufacturers are reluctant to cooperate.

\subsection{Targeting only Personal Users (76)}


Until 2011, the target audience was personal users only. Some developers argued that the first target should have been end-users in public institutions. Post 2011, the target changed to become institutional end-users. Targeting all end-users in public institutions is to general to meet the needs of those sub audiences within this group. FOSS cannot (might not, shall not, etc., depends on contents) answer and meet all needs of end-users in institutions until relevant conditions are accordant with FOSS philosophies.

\subsection{Other Linux Distribution Packages (74)}

It is very common in Linux Ecosystem to change one Linux distro to another. It depends on personal interests and/or purposes of end-users. In this sense, the question should be why Pardus instead of Ubuntu, RedHat etc. There are many advantages in using Ubuntu instead of Pardus, e.g., more software applications, compatibility, fast development, more educational supports, etc., but there are also disadvantages, e.g., less Turkish educational materials, lack of national awareness, etc. The security level can also determine the choice of OSs; a small project, controlled by a small team, might choose a different OSs to large project and team, as security against virus attack is less significant. Nevertheless, other Linux distros are generally perceived as an enemy or at least a competitor; this is even written in the principal agreements of Pardus project. Linux OSs feed each other; it is generally understood that PCSS and FOSS are feeding each other through providing ideas [4]. So, why not use cross-transfer of ideas between FOSS communities, as argued further.

\subsection{The Structure of Package-PISI (68)}

In FOSS communities, PISI is so controversial. In 2004, the Pardus team believed in PISI to best Linux option. International and national FOSS communities believed this was not the best option to retaining the projects international approach. By Pardus developing and tailoring PISI to their specific needs, they lost any ability to gain international voluntary development, align PISI with other FOSS applications and, they critically and significantly narrowed their options for development. PISI is a typical example of many unsuccessful national Linux projects across the world. Common Linux questions were asked in the Pardus project: how to install EXE programs and/or to run RPM/DEB packets in Pardus OSs? Simply it cannot (or might not) be installed and/or run. This is a short and concise answer for developing PISI. In 2004, the reasons of PISI development was declared by the Pardus teams as, at present, there are available and widely used package managers (RPM, DPKG and Portage), some of them are not satisfying our needs and requirements and some of them are in no way meeting the 'promise'. The study of developing these packets managers and so bringing them to the desired point is not easier than writing a new and more robust packet manager (see tr.pardus-wiki.org).

Pardus reasons to develop PISI were not as plausible or as transparent as they intended. There were significant advantages to joining an available international project, instead of the risks of developing new one. So, it is not accurate to state that Pardus or TUBITAK wanted to be a GNU project; sharing resources and developments internationally. The only reasoned argument for creating new PISI was to try to establish Turkish OS (Turkish language concern) and managing the file system as simply and proactively as possible and, as TUBITAK declared, to be a leader in FOSS communities. To explain in simple terms, PISI is a kind of design structure, and a preference. In the project, supporting the Turkish language is crucial for the Pardus project and TUBITAK support from stakeholders. The Pardus team had to be sure that any Turkish content should be exemplary in its use of Turkish language for full support. The Turkish language was modernized with the Latin alphabet, it has Ç, Ğ, I, İ, Ö, Ş, and Ü which are not in the English alphabet, so the Pardus team needed assurance that any software application in Pardus OSs should recognize Turkish alphabets. Unfortunately, it is not possible for all FOSS, even sometimes PCSS applications to provide this, 
e.g. Particular software may put Ç content at the end of the list, instead of between $C$ and $D$, making it incompatible. This is a common issue in the software sector. Each Linux distro has different concerns and priorities; therefore it may not always be the right decision to integrate particular software, written for particular Linux distro, to another Linux distro. So, we can conclude that Pardus created its own PISI to meet Turkish language requirements and economic usage of file system.

PISI created an unintended outcome for Pardus developers; resources were diverted onto PISI, rather than developing new projects and/or carrying out developing old projects. For example, Arslan explained that Pardus developers' skills were becoming defunct and out of date; they could not answer the needs and requests of new packages. Aslan had managed over 300 packages, including all updating and maintaining, solving possible conflicting issues, hardware concerns etc. Meanwhile, end-users requested further packages relating to their interests and needs, and criticized Pardus for not supporting more FOSS applications/preferring or migrating another Linux distro [47]. PISI opponents rightfully and publicly argued that 'the issue is not to compile packets to work' rather 'the issue is to compile packets to work as TUBITAK wishes to'.

So why did TUBITAK not support another Linux distro project, instead of creating new package management system within FOSS communities that are asking how we can standardize Linux OSs? According to Miguel de Icaza who is one of the creators of GNOME Linux distro, "the efforts to standardize on a kernel and a set of core libraries were undermined by the Distro of the Day that held the position of power. If you are the top dog, you did not want to make any concessions that would help other distributions catch up with you. Being incompatible became a way of gaining market share. The only way to fix Linux is to take one distro, one set of components as a baseline, abandon everything else and everyone should just contribute to this single Linux. Whether this is Canonical's Ubutu, or Red Hat's Fedora or Debian's system or a new joint effort is something that intelligent people will disagree until the end of the days" [48].

\subsection{Enter a Lawsuit against PDK (67)}

In June 2008, Pardus Users Association (PDK) was established by FOSS supporters, to introduce Pardus to more end-users and support FOSS projects in Turkey. At that time, the official community page, özgürlükiçin.com, was controlled by TUBITAK. Therefore, PDK decided to set up its own website pkd.org.tr, and use a logo which is a combination of a Penguin and the Pardus logo. However, in a week TUBITAK Law Department announced following: There is no factual or legal relationship or Corporation between individuals and organizations under the name of Pardus Users Association and TÜBITTAK-UEKAE itself and employees of TÜBITAK-UEKAE who are the actual creator of the Pardus System. These kinds of formations are required to get permission from TUBITAK-UEKAE, prior to any activities carried out by using the Pardus Trademark in these formations, to avoidance of possible legal disputes that may arise within the frameworks of the Law No.556 on the Protection of Trademarks Delegated Legislation and Legal Disputes Articles. In the contrary case, criminal and legal transactions will be started with the regard to relevant persons. TÜBITTAK-UEKAE is not responsible of formations which are established without any permission from TÜBITTAK-UEKAE and any activities carried out by these formations [49]. In regard to TUBITAK's irrational action, Attorney Nihad Karslı who is the president of PKD, stated that if my crime is to love Pardus, I would like to have the death sentence' [50]. TUBITAK entered a lawsuit against PDK, not to use the Pardus name and to change the logo of PDK. The court adjudged removal of the logo in PDK, and to gave the right to PDK if they are willing to keep the name of PDK. Both parties filed an appeal on its behalf. In August 2012, after over four years, the Supreme Court affirmanced the local court judgment; nevertheless, neither the court nor TUBITAK had pursued this action in court after the courts. It is clear that TUBITAK was trying to assert leadership. Dr. Yücel called these communities: özgürlükiçin.com supported by 
TUBITAK and pardus-linux.org and pkd.org.tr supported by PDK as 'enemy-brothers' [51]. After, özgürlükiçin.com has become an independent community when TUBITAK stopped its supports, these two communities started to work collaboratively but this time the Pardus project has been abandoned by TUBITAK.

\subsection{Inadequate Appropriations (62)}

There is no evidence to suggest that the project failed due to finance issues. Pardus had $50 \%$ more paid contracted developers that Ubuntu, yet believed that the budget restricted their expansion. This argument is also weakened by the fact that they had volunteer developers; though not as many as Ubuntu. Was this in fact a project management issue re-budget management and had the PISI preference diversion helped this? In 2003-2009, 3.5 Million TL and in 2009-2011, 14 Million 310 thousand TL was given to the Pardus project. This also suggests that even FOSS projects are somewhat dependent on capital to succeed. However the amount of capital is not directly proportional to the success of the project. Indications suggest that international input is much further up the list of success factors.

\subsection{Providing KDE Desktop Instead of GNOME (43)}

The Pardus team was trying to develop Pardus OSs as a replica of Windows desktop. Ubuntu OSs celebrated some unique characters with GNOME; develop what is required, not want has gone before. FOSS communities believe unique innovation is crucial, but the Pardus team, despite going against advice to use and tailor PISI, preferred to support the known KDE desktop. This suggests that the Pardus project did not have the confidence to develop innovatively using Gnome and the skill to keep it secure and/or they did not believe end-users in Turkey to be able and willing to change their own habits. Notably, GNOME was supported by Pardus 2011 after Dr. Yücel successfully accomplished a voluntary project.

\section{Lets to be Pardus Fraud-Debian}

All above complicated and complex concerns were discussed in the Pardus Tomorrow Workshop on 23-24 March 2012. In the workshop it was declared that while TUBITAK had taken all responsibilities of Pardus Institutional Versions, TUBITAK would also support FOSS communities for Pardus Individual Versions, particularly technical, infrastructure and constituting supports. In terms of accountability, TUBITAK would not only develop Pardus Individual Versions with its own contracted developers, but also provide funding for universities and private sectors to be part of the project, through acting as a facilitator. The most important decision from the workshop was to establish a 'Pardus Advisory Committee', which included 8 people who authorize strategic decisions about Pardus OSs. There was a disagreement about the committee structure; but TUBITAK gained agreement that they had the overriding vote. The structure was declared, TUBITAK management representative, Civil society organization (CSO) representative, End-users community representative, Developers representatives (one from communities, totally 2 people), Pardus solution partners representative, University (academic) representative and Public institutions representative.

Meanwhile, Pardus has become Pardus Fraud-Debian behind the scenes. Interestingly most of former Pardus developers were not surprised; indicating advanced warning. According to Arslan, there were three reasons why the decision of Pardus Fraud-Debian is not surprising: (a) in the workshop, Kaplan stated that the number of packages is limited for Pardus OSs; using Ubuntu OSs (Debian based) in the infrastructure allows thousands of packages. So, Kaptan was trying to persuade the committee to use Debian. (b) Cahit Cavit Vural was invited by TUBITAK to the workshop, instead of Erdinc Gultekin, who was previously elected as a community developer representative. After a face to face argument, Gultekin participated in the 
workshop. Vural was not given an audience. For many years, Vural has been involved in the Magma-Linux project which is Debian-based distro. This also shows that TUBITAK tried to get more information about Debian fork. (c) Interactive Whiteboards (IWs) in the scope of Fatih project have been sent to schools, with passwords; academics were unaware of this capability. For these reasons, at that time, it was impossible for FOSS communities to consider Pardus OSs [52]. Pardus Fraud-Debian was launched within three months; so communication to stakeholders was carefully controlled.

On $29^{\text {th }}$ June 2012, the Pardus Advisory Committee was held, as previously planned. In the committee Kaplan explained the reasons of Pardus Fraud-Debian. In 45 days the Vestel team (who won the tender of IWs in the scope of Fatih project) could not install Pardus original OS in IWs. There were compatibility issues; therefore the Vestel team sought professional help from TUBITAK. TUBITAK could not solve the compatibility issues either (the Pardus project team disbanded), so TUBITAK further sought professional help from a private company (this was an unnamed supplier without access to Pardus solution partners). This could have been TUBITAK's best option or a deliberate action to show TUBITAK intention to withdraw from Pardus original OSs. The private company stated that they could not solve the issues but they managed to install Debian OS without any compatibility issues. Notably, Debian provides great opportunities, particularly in localization projects and generally Debian has no compatibility issues. Consequently, the Vestel team preferred installing Debian and then moved some Pardus original technologies to Pardus Fraud-Debian [53]. Installing Pardus-Debian should not have been a significant challenge for the supplier and, conveniently, happened to align with emerging Pardus project ideals. Kaptan publicity stated that 'the Pardus team will surprise (delight) the Fatih Project, currently I can say that much. Pardus will be used in 620 thousands IWs' (many forums of Pardus and 620 Smartboards are shown in Google searches).

The new direction taken by TUBITAK is not surprising, however, the reasons given to the public are secondary to TUBITAK's need to both change direction to make the Pardus project international and to redefine their success with FOSS community support. IW has x86 technologies as a mini PC and Pardus original is based on Linux kernel, one way or another, technologically the Vestel team could have solved these issues. Notably there were positive and negative reactions, particularly academics, FOSS communities, etc. Even some specialists, particularly Mustafa Akgul, Necdet Yücel, Doruk Fisek, Sezayi Yeniay and PDK offered their support to make Pardus original compatible with IWs. The Vestel team, Ministries and TUBITAK stated that the Vestel already sent IWs to schools, so it was impossible changes. Going forward, Pardus Fraud-Debian will be used in the Pardus project. In the committee, Erol spoke for Kaptan, and put forward two reasons for the selection of Debian. Debian has over 40 thousands packets, and Pardus (PISI) is around 5 thousands (it is commonly known that more packets mean less secure which is important only if the project has a national focus [54]). In the market, there are so many companies understanding Debian. TUBITAK can find support. (TUBITAK already had Pardus support. Why did they not retain skilled developers?). The change to be beneficial, as PISI is the main reason of that Pardus OSs could not be an international project.

The author importantly does not agree with TUBITAK publicized reasons. The crucial point is 'power relationship' between TUBITAK, Ministries and FOSS Communities. During the three month period re-launch/redirection, there was no information shared with FOSS communities by TUBITAK and Ministries. So what kind of accountability has been given to the Pardus Advisory Committee; they do not appear to have been involved in the decision-making? The committee, on debating PISI, had two opposing groups: the opponent group (6 people) because (a) the method of decision making is wrong and (b) abandonment of Pardus specific technologies is also wrong due to easy and unfounded reasons; and the supporter group ( 2 people) because there are contracts and TUBITAK must adhere to the agreements. 
Yücel, Yeniay and Fisek shared information about committee debate regarding PISI in their own blogs. To summaries,

'During the meeting, it is asked over and over again that what the scope of authority of the Pardus Advisory Committee was; the response was 'it would be decided in here'. Naturally our request was all decisions. Erol stated that 'unless decisions place our (TUBITAK) agreements in conflict with what has been promise'. The definition of the Pardus Advisory Committee has been replaced as: 'taking decisions on matters which fit in with TUBITAK's existing contracts'. We were dancing around this sentence for at least half an hour. Erol initially asked that 'regarding migrating Debian, I want to see the first committee decision as unanimous or at least by majority'. Intrinsically, none of us did accept it. The Advisory Committee is not responsible for approving previously taken decisions; it is responsible for making decisions. Afterwards, Erol requested 'it is alright, let's take all decisions, and however giving up PISI would be an immoveable subject in the framework of the advisory committee'. As a matter of course, we did not accept restricting our will. Erol further stated that 'if you are not signing the agreement of giving up PISI, then let's make decision about only the individual version and not including the institutional version', we did not agree. Meanwhile, we learned that the Pardus Advisory Committee is still not officially established. We again argued 'why has the committee not been held for three months, we are gathering together after you have taken all important decisions' [51].

Pardus developers, FOSS communities, academicians have no power in the decision-making process; being informed after decisions were taken. Therefore some developers started to satirically call the 'Smart Board' as 'Smart/less Board' with 'Pardus Debian' by Aggravated Fraud. During the decision-making, the Pardus community had been voluntarily developing Pardus original OSs which is called as Pardus \#Anka. This forking initiative is aimed to continue and develop old Pardus OSs by the Pardus community who are insisting on using old Pardus technologies. The question should be that Pardus \#Anka is the Pardus fork or a continuation of the Pardus project, like Pardus 2012. The community declared that if TUBITAK do keep pushing Pardus Fraud-Debian; they would be free to continue the Pardus project, because TUBITAK would not retain project control. Alternatively, if TUBITAK do reverse their decision or continue to support to Pardus original, Pardus \#Anka would be Pardus fork, but TUBITAK would be a sponsor only. Thus within the latest news, Pardus \#Anka has become Pardus 2012-13 Original; and has been released since February 2013. Google model would be used in the development process of Pardus \#Anka. First the focus is solving old Pardus shortcomings and then adding new technologies. All these studies would be based on Free Software Philosophy through drawing its strength from the community (pardus-anka.org).

\section{Reasoning Techno-Social Policy of FOSS}

To sum up, Pardus had been developed for nearly one decade but the project has been abandoned by TUBITAK overnight. So why has TUBITAK been trying to accomplished Pardus? According to most developers, the Pardus project failed its project aims and objectives. Nevertheless, GNU projects never fail because their codes are open and available on the internet (knowledge/skill share for the greater good). Therefore, it might be fair to state that the Pardus project could have accomplished more, but for PISI. Currently, most former Pardus developers have started their own private companies to provide FOSS and Linux OSs solutions; some of them pursuing this aim within the private sector. So though the Pardus project may be evaluated as a failure, in terms of its objective, it resulted in increased awareness and usage of FOSS applications in the ICT market in Turkey.

Whist the author agree with the decision of Debian, he does not condone the decision-making process or lines of accountability. TUBITAK or any institutions should not directly develop FOSS applications and Linux OSs, but support and promote available FOSS applications. If public sector institutions support the 
use of FOSS, FOSS will naturally develop greater efficiency and create FOSS ecosystem within and supported by the private sector. It is argued that even using Linux OSs in servers might be enough to create an initial Linux ecosystem. If 'Interoperability Framework Guides' and 'Standardizations' as in the ICT Project Preparation Guides (July 2005, August 2010, September 2011, July 2012, July 2015 [55]) are followed, it will drive the concepts to create FOSS ecosystem in public sectors. Unfortunately, they are not followed (clearly seen the Prime Minister reports [56]). Why did the Turkish Government start the Pardus project then? The Government wanted to use/test Pardus in public sectors, to understand the challenges to better evaluate PCSS solutions and to use Pardus as leverage to obtain better ongoing deals from Giants (e.g. Microsoft).

If the real aim is to use and support FOSS nationally and to influence FOSS communities, FOSS policy should be clearly written and supported by 'state policy' whilst providing the flexibility to be innovative, instead of 'government policy', restricting and stabilizing Pardus and using Pardus as leverage to obtain better deals with the Microsoft or other future PSCC corporations. In January 2012 Caglayan who emphasized that 'when there was no hope in the Fatih project, the Pardus project team has moved from TUBITAK to Information Technology Institute, and the Fatih project was renamed as 'the Pardus for the Fatih Project' at the end of October 2011. We hoped this was possible. A few days later, a senior executive told me in front of all workers in the institution 'Microsoft has made 5TL deduction for each license. Just recently the Minister of the UBAK told the senior executive that the Fatih project is already committed to Microsoft; that was an unseemly and unprofessional comment. Afterwards, we heard from a senior executive that in the scope of the Fatih project, they were grateful the Pardus project had given Microsoft a hard time. At least I realized that renaming 'the Pardus for the Fatih Project' is nothing other than stalling. We witnessed that researchers, who we trust; we respect we know they do great job, were suspended from their duties and transferred to the lower-level tasks. The media and the outside world never knew what was going on; it could not be' [57]. (Notably, there was enough evidence of mismanagement of TUBITAK and the Pardus Project team to usurp or at least influence change in how they operated. The protection of the Government in Turkey was enough to persuade TUBITAK that they were not answerable to stakeholders). In April 2012, Arslan emphasized similar issues; 'TUBITAK changed its management team in winter 2011. As a result of a comprehensive meeting in TUBITAK, it was decided not to include Pardus OSs in the Fatih project. In the meeting, we were told that Pardus OSs played the role of hammer price (leverage), so they have gained an advantage of $5 \$$. Therefore it cannot be denied the Pardus role in this success. When the team heard about it, they were demoralized and many resigned. Blood loss continued increasingly after this day'. [58] In this sense, there is only one conflict, 5TL or 5\$. The bargaining transactions occurred by strategic interactions for offering and bidding in price settings within imperfect market competition. It is clear that there were not only top-down decisions to use Pardus OSs to get better deals from the Microsoft, but also to change the structures of TUBITAK, and so the Pardus project. Notably, this kind of interaction not only occurred in the Fatih project, but many other examples of leverage techniques used against the Microsoft are evident. According to Zaman Newspaper in June 2004, in the Microsoft Partners in Learning protocol meeting, the Minister, Huseyin Celik stated that they act selectively to get the cheapest and the best quality of education. We will reach a conclusion without delay. Question, The Ministry believes in effective and efficient use of public funds. There is no such a thing as dependent company (lock-in), so you see there is not a business partnership with Bill Gates [59]. The Public Sector Linux Competency Centre (Linux Training) was launched by the MoNE and IBM's contribution in June 2005, but could not have been operating. According to FazlaMesayi Website, in the opening meeting of the centre, the Minister, Huseyin Celik also stated that Turkey complies with the new world orders. The speculations after Bill Gates visit to Turkey are not real, particularly in the parliamentary written questions, as is there a 
Microsoft monopoly in Turkey? [60] However, regarding to the protocols of 'Microsoft Partners in Learning' (May 2004, July 2009, May 2011 and May 2015) [61], it purchased computers within all educational projects, Microsoft OS(s) and Microsoft Office(s), and necessary software (except Adobe products) were installed. Additionally, Microsoft supported all pilot studies. The MoNE did not pay any fee for Microsoft supports; that are donations from the Microsoft Corporation in the $\$ 30$ millions projects and unfortunately end up lock-in for MEBBIS which is the online educational portal for Turkey.

The latest example is that in the Fatih project, 85 thousands IWs have been sent to schools, and the plan is to send 620 thousands more across to Turkey since 2013-14. In 85 thousand IWs, two OSs (Windows 7 and Pardus Fraud-Debian) are installed but Windows 7 is a default OS and IW is not equipped with an external keyboard to select Pardus Fraud-Debian when IW opens. Importantly, in the tender specifications, there is no external keyboard requirement. Besides, USB ports, IWs are locked and under password control. Even teachers, who carry their own keyboards in schools, need to take the key to open the USB box and to know the password to use USB ports. In other words, using Pardus Fraud-Debian is impossible. Although, on the internet, some teachers are sharing passwords to support teachers in the use of Pardus, there is an authorization issue because it is a public institution. Evidently any issues related to OSs are not covered by the guarantee [62]. ICT formatters recommend that it is not advised to change the system, particularly at this stage. Thus this information evidently shows unprofessionalism in the Fatih and Vestel teams, or at least their own ignorance in regards to Pardus Fraud-Debian. The literature regarding 'Indirect Exclusionary Effect', that of a default option preference (actually a design choice) has not reached a consensus of whether this is correct installation, but it is emphasized that this is a method of monopolizing the market, with contractual powers, e.g. in the ICT history, the Microsoft Corporation made illegal to delete Windows icons, Media Players, Internet Explorer (IE), etc. from OEMs' products. Despite the fact that Microsoft monopolized the ICT market, the courts in the USA and the EU had different decisions for different concepts [63]. Notably, the current and future argument is 'Secure Boot' or also called as 'Restricted Boot'.

In summary, in the literature of sociology, each theoretical tradition has diverse thoughts on the subject of emergent technology, and so software. For instance, functionalists highlight fundamentals of rationalization facilitated by capabilities of technology to diminish limits of time and space, and they also stress unique standing cultures within emerging landscape. Symbolic integrationists more likely focus on the way technology reinforces shared cultural values and organic harmony. Critical theorists question particular influences of technological change on techno-social political consideration and reliability and validity of civil society. And conflict theorists concentrate on the control of elite over public and their political power through techno-social cultural hegemony and therefore forewarn increasing legal and/or illegal externalities. In this sense, this particular paper has attempted to be a conflict theorist, to identify techno-social policy of FOSS in Turkey that can be concisely diagram by the principle of Process Tracing Approach, as in the following diagram. It is argued in this paper that in the scope of the Pardus project, there are particular causal effects that might be categorizable as: Non-FOSS Policy (the Project could not interiorize FOSS philosophy, and so there is no an appropriate FOSS policy); Management Failure (they are so many precedents in the project history as argued in this paper); TUBITAK and Government (decision makers could not accept FOSS movements, e.g. in FOSS, there is no omniscient authority); PISA and JIRA (one pragmatic decision followed another pragmatic decision, like path dependent mobility); Brother Enemies (suing one of FOSS Community and then to expect working in harmony) and Indirect Market Forces (Network Effect, Indirect Exclusionary Effect, etc.). Nevertheless, all these causal effects have particular meaning thorough particular causal mechanisms that might be categorizable as: Pragmatic Decision-Making Strategy (one particular decision which works satisfactory does not mean there is no 
negative externality, such as one of outcome is Microsoft Hegemony); National Interests (in FOSS movements, there is no such a thing as 'Nationalism', the fundamental principle is supposed to be 'Globalness', therefore Kemalizm and Turkishness does not always lead (or at least promise) positive consequences); Bureaucratic and Autocratic Leadership (there are three main thoughts in FOSS philosophy; Freedom, Equality and Solidarity [4]. These are totally against Bureaucratism and Autocratism); Monopolistic Competition (in Turkey, there is no precise lobbying regulation and an unproductive national competition authority; therefore, Turkey is described as the 'Nation of No Statutory Rules' [64]); Procrustean ICT Strategy (in ICT literature, it is widely known that one-size-fits-all-software-system is one of the Giant strategies to ensure their hegemonic positions, but it is ineffective and risky due to the fact that there national security issues and privacy concerns) and Technological Singularity (in FOSS communities, the fundamental issue is not able to be 'Globalness', that is so clear in the Pardus project. Therefore, the spirit of Pardusness was not cable of following technological singularity). Consequently, these causal effects through causal mechanisms have lead to the conclusion of causal inferences; Conflict and Loneliness, and so ensuring Techno-Social Digital Obsolescence (see Fig. 1).

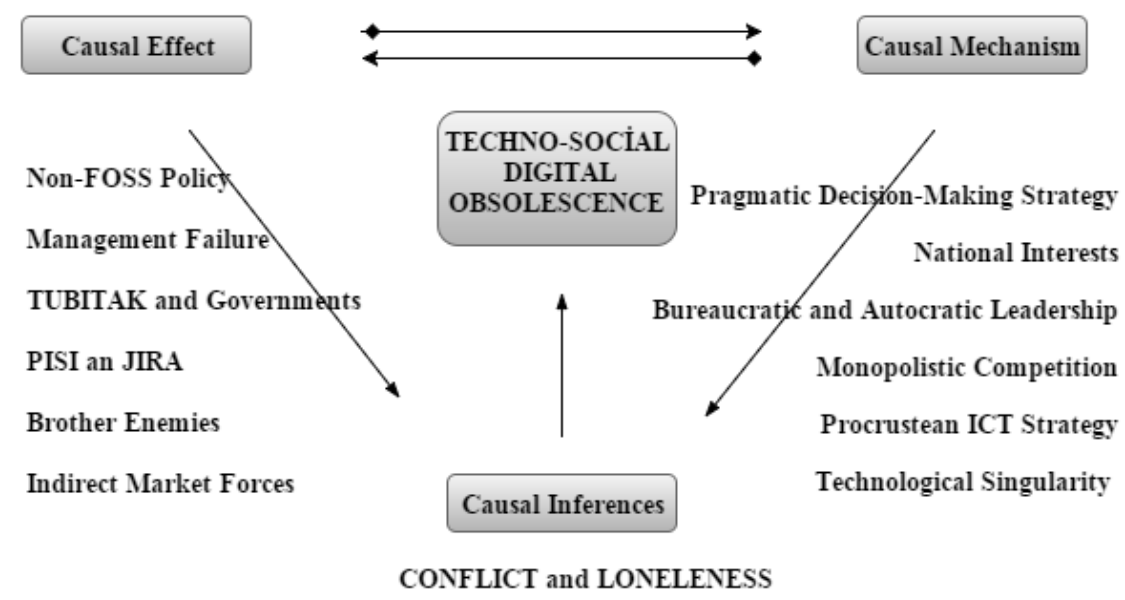

Fig. 1. Techno-social policy of FOSS.

\section{Conclusion}

Evidently the Linux development process is so complicated and complex that there have been various actors who might be visible and/or invisible within international network, but these actors have direct influences upon FOSS projects. This study has questioned 'how to succeed or failure in Linux project'. The study has also discussed how the Pardus project failed its stated aims and objectives (2004 \& 2011), and simply used the project as leverage to obtain better ongoing deals from the Microsoft. The actual outcome is that the project existence resulted in both improved deals with Microsoft, but also improved ICT initiatives, particular in the software sector in Turkey. The Governments always stated that the software industry is defined as a 'priority sector' but this aim was not a revelation for Turkey, in fact, it was actually included in the Sixty Five Year Plan (1990-1994) also stated software industry as the priority sector [65].

Admittedly and evidently, there is a significant distinction between learning and education. While learning might be considered as a personal development and improvement process, education is an intentional social project through particular goals and objectives usually to meet a complex social good, not even a public good [66]. This social project orientates, manipulates and even controls society. The Government in Turkey has shaped Turkey as a Windows-society. In this study, the author does not attempt to distinguish between Windows and Linux and then theoretically claim that either one of them is 'the best' 
because of the complexity of dynamic societies and ongoing technological changes. Rather, the argument of Windows and Linux Societies is more philosophical through socio-economical perspective (FOSS and PCSS are alternatives of each other). Currently there is no longitudinal and multivariate data, and there is a lack of information on whether these two societies are different in terms of learning, teaching and/or understanding of the world etc., [67]. Thus, there is no academic clarification yet to determine and define Windows and Linux societies; nevertheless there is an option to be one of them. As Alice Wonderland, Alice asks 'would you tell me, please, which way I ought to go from here?' Cheshire cat answers 'that depends a good deal on where you want to get to,'

Currently the Pardus project developers are no longer part of the project; but still there is some development (no information how), e.g., there are agreements to use Pardus Fraud-Debian between some Ministries and TUBITAK, particularly the Ministry of National Defense. The future of Pardus Fraud-Debian will be shaped in the scope of Fatih project. There is no clear future for the Fatih project whilst they have not defined the four knowledge(s), used in 'knowledge-based economy', as OECD (1996) emphasized: know-what ('facts'), know-why ('scientific knowledge of the principles and laws of natures'), know-how ('skills or the capability to do something') and know-who ('information about who knows what and who knows how to do' is the crucial concept), as emphasizing know-that and knowledge-that [68]. The Fatih project future is also unclear because there is no precise National ICT Policy in Turkey (see e-Transformation and Issues Report by the Prime Minister in 2012, and 25th Meeting of the High Council of Science and Technology Report, January 2013) and Education System in Turkey is highly centralized and has been suffering by institutional inertia and inertia in education issues [69], as "Schools mirror society; they do not drive it" [70].

The Government in Turkey is so established, and has been criticized for acting as a 'kleptocratic government' in the scope of the Fatih project by Turkey' Opposition parties, e.g. MP, Demirel, in 2012 [71]. Indeed, the argument of how the Governments in Turkey has been acting as 'a kleptocratic government' by Opposition parties or 'a cooperative governance' as declared by the Governments since 2005 [72], or other governance models (e.g. Anglo-Government, Polycentric Government etc.) is another research question. As a rare instance of a more knowledgeable public stakeholder, who can consider across several disciplines, the author feels it is his responsibility to record events in Turkey and principally, attempt to persuade a modify in outcomes in techno-social policy. In this sense, this particular area is a part of cybernetic, as to orchestrate (manipulate and propagate) techno-social interaction for the actual purpose of establishing control mechanisms. In a broad term, techno-social policy is for cybernetic as "the ideal of a stable society, expressed by objectively controllable social mechanisms" [73].

\section{References}

[1] Ramsey, D. (2008). The SoftWhere 2008: UC San Diego Researchers Pioneer Emerging Field of 'Software $\begin{array}{lllll}\text { Studies'. } & \text { Retrieved } & \text { April } & \text { 2015, from }\end{array}$ http://ucsdnews.ucsd.edu/newsrel/science/04-08fSoftWhere2008.asp

[2] St. Amant, K., \& Still, B. (2007). Handbook of Research on Open Source Software: Technological, Economic, and Social Perspectives. Idea Group Reference.

[3] Knuth, D. E. (1972). The Art of Computer Programming. Reading, MA: Addison- Wesley.

[4] Weber, S. (2004). The Success of Open Source. Cambridge, Mass.: Harvard University Press.

[5] Williams, R., \& Edge, D. (1996). The social shaping of technology. Research Policy, 25, 856-899.

[6] Griffiths M. (2012). Open source and open standards by house of parliament, parliamentary office of science and technology of the UK. Retrieved 2015, from http://www.parliament.uk/briefing-papers/POST-PN-414 
[7] Wheeler, A. D. (2007). Why open source software / free software (OSS/FS)? Look at the Numbers!. Retrieved 2015, from http://www.dwheeler.com/oss_fs_why.html

[8] Peters, M. A. (2013). Radical openness: Creative institutions, creative labor and the logic of public organization in cognitive capitalism. Knowledge Cultures, 1(2), 47-72.

[9] North, D. C. (1990). Institutional Change, and Economic Performance. Cambridge: Cambridge University Press.

[10] Van, E. S. (1997). Guide to Methods for Students of Political Science. Ithica: Cornell University Press.

[11] George, A. L., \& McKeown, T. M. (1985). Case studies and theories of organizational decision making. Advances in Information Processing in Organizations.

[12] Evans, P. (1995). The use of theory in comparative politics: A Symposium. World Politics, 48(1), 1-49.

[13] Çetin G., \& Işıngör, A. (2003). Does your army still use your mother OS? Retrieved 2015, from http://www.tankado.com/ordunuz-hala-annenizin-iletim-sistemini-mi-kullanyyor

[14] Ministry of Development. (2013). Information society strategy renewal, workshop evaluation report. Retrieved 2015 , from http://www.bilgitoplumu.gov.tr/?s=At\%C3\%B6lye+\%C3\%87al\%C4\%B1\%C5\%9Fmas\%C4\%B1+De\% C4\%9Ferlendirme+Raporu

[15] Gray, J. (2010). Readers' choice awards 2010 linux journal. Retrieved October 29, 2015, from http://www.linuxjournal.com/content/readers-choice-awards-2010

[16] Sowe, K. S. (2009). A new kid on the block: The turkish pardus linux distribution. Retrieved 2015, from https://joinup.ec.europa.eu/community/osor/case/new-kid-block-turkish-pardus-linux-distribution

[17] Eren, M. (2012). Users and developers of pardus critics report. Retrieved March 20, 2015, from http://meren.org/tmp/PardusElestirileri.pdf

[18] Yücel, N. (2912). After pardus tomorrow workshop. Retrieved March 25, 2015, from http://www.nyucel.com/2012/03/pardusun-yarn-calstaynn-ardndan-2.html

[19] Erkan Tekman blogs. Retrieved 2015, from http://blog.erkantekman.org/

[20] Tekman, E. (2009). Hasta la vista... Pardus. Retrieved April 1, 2015, from http://blog.erkantekman.org/2009/04/01/hasta-la-vista-pardus/

[21] Tekman, E. (2008). Ah mazi... reloaded. Retrieved August 17, 2015, from http://blog.erkantekman.org/2008/08/17/ah-mazi-reloaded/

[22] Tekma, E. (2011). Pardus YN: Ana Sözleşme 2.0. Retrieved June 1, 2015, from http://blog.erkantekman.org/2011/06/01/pardus-yn-ana-sozlesme-2-0/

[23] Fisek, D. (2010). The argument of Jira. Retrieved July 8, 2015, from https://www.mail-archive.com/gelistirici@pardus.org.tr/msg09762.html

[24] Prime ministry / state planning organization. (2010). Retrieved March 20, 2015, from http://www.bilgitoplumu.gov.tr/Documents/1/BT_Strateji/20100323_BTS_Degerlendirme_V.pdf

[25] TUBITAK. (2013). 25th meeting of the high council of science and technology report. Retrieved 2015, from http://www.tubitak.gov.tr/sites/default/files/btyk25_yeni_kararlar_toplu.pdf

[26] Yücel, N. (2012). The war between microsoft and universities. Retrieved April 25, 2015, from http://nyucel.blogspot.co.uk/2012/04/microsoftun-universitelerle-savas.html

[27] Tolu, H. (2014). The politics of ICT4ED project (Fatih) in turkey. Policy Futures in Education, 12(6), 832-849.

[28] Kandemir, B. (2012). What happened to pardus. Retrieved January 22, 2015, from http://comments.gmane.org/gmane.linux.pardus.devel/401

[29] Tekman, E. (2012). Pardus unfavorable history (2007-2011). Retrieved July 3, 2015, from http://blog.erkantekman.org/2012/07/03/pardusun-makus-tarihi-2007-2011/ 
[30] Tekman, E. (2009). Pardus: 2003-2008 and future perspectives. Retrieved November 24, 2015, from http://blog.erkantekman.org/2008/11/24/pardus-2003-2008-ve-gelecege-bakis/

[31] Dede, M. B. (2009). The big target in the pardus project. Retrieved November 8, 2015, from http://www.yenisafak.com/teknoloji/pardustan-buyuk-hedef-221875?p=1

[32] International Development Association. (2003). Open Source Migration Guidelines, 2003, Retrieved 2015, from http://ec.europa.eu/idabc/en/document/1921.html

[33] Toprak, M. (2005). The development of a NATIONAL operating system. Turkish Grand National Assembly. Retrieved February 24, 2015, from http://www.tbmm.gov.tr/develop/owa/yazili_sozlu_soru_gd.onerge_bilgileri?kanunlar_sira_no=3047 1

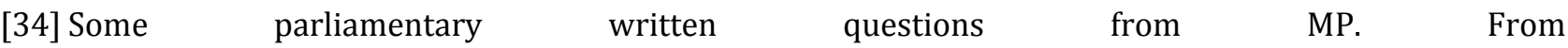
http://www.tbmm.gov.tr/develop/owa/yazili_sozlu_soru_sd.sorgu_baslangic

[35] Ministry of environment and forestry. (2008). Turkish Grand National Assembly. Retrieved March 13, 2015, from http://www2.tbmm.gov.tr/d23/7/7-2983c.pdf

[36] Ministry of national education. (2008). Regarding the Licensed Used Software. Retrieved March 13, 2015 , https://www.tbmm.gov.tr/develop/owa/yazili_sozlu_soru_gd.onerge_bilgileri?kanunlar_sira_no=6039 9

[37] Aksünger, E. (2012). The general assembly of grand national assembly of Turkey minutes. Turkish Grand National Assembly. Retrieved February 21, 2015, from http://www.tbmm.gov.tr/develop/owa/Tutanak_B_SD.birlesim_baslangic?P4=21133\&P5=H\&page1= 72 \&page $2=72$

[38] The prime minister / state planning organization (SPO). (2008). Turkish Grand National Assembly. Retrieved March 13, 2015, from http://www2.tbmm.gov.tr/d23/7/7-2983c.pdf

[39] TUBITAK-UEKAE would use Pardus OSs in all hardware and recommend using Pardus into all TUBITAK institutions.

[40] Akgül, M. (2008). What does free software world want? Retrieved 2015, from http://www.ankarabarosu.org.tr/Siteler/1944-2010/Dergiler/BilisimveHukukDergisi/

[41] TUBITAK. (2013). 2242- undergraduate students software project competition 2013. Retrieved February 23, 2015, from http://www.tubitak.gov.tr/sites/default/files/2242_2013_proje_rehberi.pdf

[42] Yücel, N. (2013). TUBITAK Returned from Wrong. Retrieved February 13, 2015, from http://nyucel.blogspot.co.uk/2013/02/tubitak-yanlstan-dondu.html

[43] TUBITAK. (2013). 2242- Undergraduate students software project competition 2013 - important $\begin{array}{llll}\text { concepts. } & \text { Retrieved 23, 20bruary } & \text { 23, from }\end{array}$ http://www.tubitak.gov.tr/tr/yarismalar/yazilim-projeleri-yarismasi/icerik-onemli-hususlar

[44] Arslan F. (2012). Debian-based new Pardus. Retrieved June 27, 2015, from http://blog.arsln.org/debian-tabanli-yeni-pardus/

[45] Gorsel, G. (2010). When we are developing? Retrieved March 22, 2015, from http://blog.gokmengoksel.com/2010/03/ne-zaman-gelistiriyoruz/

[46] ShiftDeleteNet. (2013). In the fatih project, it will be in Windows 8! Retrieved January 10, 2015, from http://shiftdelete.net/fatih-projesinde-windows-8-de-olacak-34192

[47] Arslan, F. (2012). Why the system package of PISI was chosen? Retrieved February 7, 2015, from http://pardus-kullanicilari.uludag.org.narkive.com/TQtjRVE4/pisi-paket-sistemi-neden-secildi

[48] Steven, J. (2013). Linus Torvalds on the Linux desktop's popularity problems. Retrieved September 3, 2015,

from 
http://www.zdnet.com/linus-torvalds-on-the-linux-desktops-popularity-problems-7000003641/.

[49] TUBITAK. (2008). Publicizes. Retrieved July 3, 2015, from http://web.archive.org/web/20080731191348/http://cekirdek.pardus.org.tr/ tekman/zangetsu/bl og/2008/07/03/10/

[50] Dede, M. B. (2013). TUBITAK, the first is suing, then given thanks. Retrieved May 18, 2015, from http://www.melihbayramdede.com/tubitaktan-once-dava-sonra-tesekkur.html

[51] Yücel, N. (2013). The trial of the pardus users association has ended. Retrieved April 25, 2015, from http://nYücel.blogspot.co.uk/2012/08/pardus-kullanclar-dernegi-davas.html

[52] Fisek, D. (2013). The pardus project has over, starting a new distribution. Retrieved July 1, 2015, from http://zzz.fisek.com.tr/seyir-defteri/pardus-dagitimi-bitti-yeni-bir-dagitim-basliyor/

[53] Yeniay, S. (2013). After the pardus advisory board. Retrieved July 5, 2015, from http://sezaiyeniay.wordpress.com/2012/07/01/pardus-danisma-kurulunun-ardindan/

[54] New study reveals widespread use of vulnerable open-source components by the global 500. Retrieved 2015 , from http://www.sonatype.com/News/Press-Releases/New-Study-Reveals-Widespread-Use-of-Vulnerable -Open-Source-Components-by-the-Global-500.

[55] State planning organization information society department. (2015). ICT Project Preparation Guides Retrieved 2015, from http://www.bilgitoplumu.gov.tr/yatirim/

[56] Rime, M. (2012). E-state: Concept and general issues. Retrieved 2015, from http://www.tbmm.gov.tr/arastirma_komisyonlari/bilisim_internet/docs/sunumlar/Koordinasyon_Ca lismasi_Sunum-ea_06062012_1045.pdf

[57] Caglayan, O. (2012). My pardus histor., Retrieved January 1, 2015, from http://ozancaglayan.com/2013/01/10/benim-pardus-hikayem/

[58] Arslan, F. (2012). My pardus history and after then. Retrieved April 22, 2015, from http://blog.arsln.org/pardus-ayrilisim-ve-sonrasi/

[59] Zaman, N. (2004). It was signed a protocol of cooperation in education with Microsoft. Retrieved June 22, 2015, from http://haber.gazetevatan.com/0/30276/1/Haber

[60] FazlaMesai.net. (2005). Public sector linux competency centre has been opened. Retrieved June 21, 2015, from http://www.fazlamesai.net/?a=article\&cmode=nested $\&$ sid=3027

[61] Ministry of national education. (2015). The collaboration project between ministry of national education and Microsoft. Retrieved May 13, 2015, from http://www.meb.gov.tr/meb-ile-microsoft-turkiyeden-is-birligi-projesi/haber/8695/tr

[62] Vestel corporation. (2013). Interactive whiteboard user guide by vestel corporation, Retrieved 2015, from http://fatihprojesi.meb.gov.tr/icerikeklenti/e230212133350.pdf

[63] Page, W. H. (2009). Mandatory contracting remedies in the Microsoft cases. Antitrust Law Journal, 75(3).

[64] Chari, R., Hogan, J., \& Murphy, G. (2010). Regulating Lobbying: A Global Comparision. Manchester: Manchester University Press.

[65] World bank. (1993). Turkey: Informatics and Economic Modernization, A World Bank Country Study. The World Bank, Washington, D.C.

[66] Robertson, S., Mundy, K., Verger, A., \& Menashy, F. Public private partnerships in education: New actors and modes of governance in a globalizing world. Cheltenham, Edward Elgar, 21-42.

[67] Ghosh, R. (2005). Free/libre/open source software: Policy support flosspols, an economic basis for open standards. Retrieved 2015， from http://publications.becta.org.uk/display.cfm?resID=25907

[68] Organisation for Economic Co-operation and Development (OECD). (1996). The Knowledge-Based 
Economy, Paris.

[69] Baykal, A. (2013). The condition of education. Retrieved 2015, from http://inet-tr.org.tr/inetconf16/sunum/fatih-alibaykal.pdf

[70] Goodlad, J. I. (1997). Making democracy safe for education. Education Week, 1997.

[71] Demirel, M. P. R. (2012). The fatih project costs No.7/2653. Turkish Grand National Assembly. No.7/2653. Retrieved January $\quad 3, \quad 2015$, from http://www.tbmm.gov.tr/develop/owa/yazili_sozlu_soru_sd.onerge_bilgileri?kanunlar_sira_no=99377

[72] Capital markets board of Turkey. (2005). Corporate Governance Principles. Retrieved 2015, from http://www.spk.gov.tr/displayfile.aspx?action=displayfile\&pageid=55\&fn=55.pdf

[73] Tiqqun. (2010). The cybernetic hypothesis. The Anarchist Library Anti-Copyright.

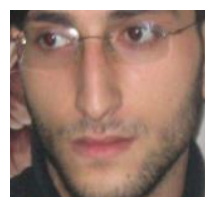

Hüseyin Tolu was born in Turkey and currently is working at the Recep Tayyip Erdogan University in Turkey; as a lecture of sociology and computer. Tolu has finished his $\mathrm{PhD}$ at the University of Bristol in the United Kingdom in 2014. Tolu has eight years' academic experience in techno political management brokering (the trinity mechanisms of techno-politics in Cybernetic) to conceptualize current and future technology in social practices. In academia, Tolu has been interested in software related subjects, in particular cybernetic, sociology, futurism, globalization, glocalization, privatization, liberalization, educational policy, software policy, proprietary close source software, free open source software, public-private-partnerships, new public management, copyright, copy-left, digital right management, governance, digital divide and poverty, artificial and humanistic intelligences, technological and economical singularity, future education, philosophy and market (cynic, hedonist, dandy, materialist, activist, etc.), new social movement, scapegoatism, public-relationship, propaganda, cyber-luddism, etc. 